\title{
Detection of ground movements in Montjuïc (Barcelona) using TerraSAR-X data
}

\author{
Luca Tanteri ${ }^{1}$ (D) María Cuevas-González ${ }^{2} \cdot$ Núria Devanthéry $^{2} \cdot$ Michele Crosetto $^{2}$ • \\ Nicola Casagli ${ }^{1}$
}

Received: 26 June 2015/Accepted: 10 December 2015/Published online: 2 January 2016

(C) The Author(s) 2015. This article is published with open access at Springerlink.com

\begin{abstract}
In this study, 28 StripMap TerraSAR-X images were processed using a Persistent Scatterer Interferometry technique in order to detect and analyze superficial deformation phenomena affecting the hill of Montjuïc in Barcelona between December 2007 and November 2009. The results show significant displacement values in two main areas affected by different types of superficial displacements, specifically compaction in a former quarry refill and sliding processes. Displacement values of up to $12 \mathrm{~mm} /$ year along the line of sight of the satellite were detected in the area near the Pèrez de Rozas baseball stadium whereas values of up to $7 \mathrm{~mm} /$ year were found in the vicinity of Costa i Llobera gardens. For each deformation area, high resolution deformation velocity data were analyzed and integrated with historical images and field data to interpret the detected phenomena.
\end{abstract}

Keywords SAR - Persistent scatterers - TerraSAR-X · InSAR · Ground deformation · Montjuïc

\section{Luca Tanteri}

luca.tanteri@unifi.it

María Cuevas-González

mcuevas@cttc.cat

Núria Devanthéry

ndevanthery@cttc.cat

Michele Crosetto

mcrosetto@cttc.cat

Nicola Casagli

nicola.casagli@unifi.it

1 Department of Earth Sciences, University of Florence, Via G. La Pira 4, 50121 Firenze, Italy

2 Centre Tecnològic de Telecomunicacions de Catalunya (CTTC), Av. Gauss 7, 08860 Castelldefels, Barcelona, Spain

\section{Introduction}

Satellite-based radar interferometric techniques represent a powerful tool to measure and monitor ground displacements (Massonnet and Feigl 1998; Hanssen 2001). The focus of this paper is on a particular implementation of Persistent Scatterer Interferometry (PSI), a technique which is based on the use of a stack of images acquired by a satellite over a given area at different times. The term PSI is used in this work to indicate a number of different techniques including the Permanent Scatterers approach (the first PSI technique proposed by Ferretti et al. 2000), other techniques based on Persistent Scatterers (PSs), those based on distributed scatterers (Berardino et al. 2002), and other hybrid methods. PSI has been widely used for the detection, characterization, and monitoring of different phenomena such as subsidence (Ferretti et al. 2004; Dixon et al. 2006; Galloway and Burbey 2011), slope instability, and landslides (Farina et al. 2006; Colesanti and Wasowski 2006; Lu et al. 2012), deformation in urban areas (Ng et al. 2012; Lubitz et al. 2013), etc. The PSI technique allows obtaining a comprehensive outlook of the deformation phenomena occurring in wide areas while, at the same time, maintaining the capability to measure individual features such as buildings or infrastructures. However, there are some limitations of the PSI technique worth mentioning: (1) the PSI technique relies on coherence and, therefore, is opportunistic, which means that it is only able to estimate deformation over the available PSs, i.e., those points where PSI phases maintain good quality over time to get reliable deformation estimates, e.g., see Hanssen (2001); (2) PSI suffers limitations in its capability to measure "fast" deformation phenomena due to the ambiguous nature of PSI observations, which are $2 \pi$ wrapped. Although it is difficult to quantify what "fast" 
means, in the case of TerraSAR-X data, differential movements of up to $0.77 \mathrm{~cm}$ of displacement in 11 days between pairs of PSs can be measured (Crosetto et al. 2010); (3) the spatial sampling is variable and, as the availability of PSs depends on coherence, in urban areas the sampling will probably be reasonably good but PSI tends to fail in vegetated and forested areas (Ferretti et al. 2000; Berardino et al. 2002). In addition, PS locations are not known before processing; and 4) the deformation measurements are made in the direction of the Line-OfSight (LOS) of the satellite (Hanssen 2001).

In this study, 28 TerraSAR-X images spanning the period December 2007 to November 2009 were used. These images were processed using the PSI chain of the Geomatics (PSIG) Division of CTTC (Crosetto et al. 2011; Devanthéry et al. 2014). The PSIG processing was performed for the entire metropolitan area of Barcelona leading to the detection of several areas affected by superficial displacements, including the hill of Montjuïc where some areas affected by ongoing superficial displacement were found. The results of the PSIG processing of the TerraSAR-X data for this hill are shown and discussed in this article.

\section{Study area}

The hill of Montjuï is a broad shallow hill (height $184.8 \mathrm{~m}$ a.s.l.) situated in the urban area of Barcelona (Catalonia, Spain), on the northeast coast of the Iberian Peninsula (Fig. 1). On a flat coastal area of approximately $5 \mathrm{~km}$ wide (NW-SE direction) by $30 \mathrm{~km}$ long (NE-SW direction), limited by the mountain range of Collserola to the west, by the Llobregat river delta to the southwest and by the Besòs river to the north. This plain covers an area of $170 \mathrm{~km}^{2}$ of which $101 \mathrm{~km}^{2}$ are occupied by the city itself.

From a geomorphological point of view, Montjuïc represents an "island" among the flat surrounding areas that are characterised by recent alluvial sediments, mainly of the Llobregat river delta in the southern part and of other minor streams coming from the surrounding hills (Serra de Collserola) in the northern part.

The slope angle map (Fig. 2b) and the profile A-B show the morphological aspect of the hill, characterized by steep slopes on the side facing the harbour and in the southern part and a relatively flat top.

The lithology of the hill is characteristic and different from the surrounding reliefs such as Serra de Collserola, the hills of Monterols, El Putget, El Carmel, and la Rovira, that are composed by metamorphic rocks and sandstones of the Paleozoic age (between 500 and 300 million years) (IGC 2010).

Montjuïc geology is characterized by marine facies of shallow waters (Alfaro et al. 2001), consisting of a thick strongly silicified detrital succession (Parcerisa Duocastella et al. 2001) in particular Miocenic arcose sandstones with levels of marls with abundant fossils of marine fauna and plants, locally covered by more recent fluvial terrace deposits. The thickness of these materials exceeds $200 \mathrm{~m}$, as can be seen in the scarp facing the harbour.

The Miocenic sandstone is commonly named "Montjuïc Sandstone"(Lourenço et al. 2004), and it is mainly composed of quartz (80-90\% volume) and feldspars (orthoclase and plagioclase $<10 \%$ volume); to a minor degree it contains fragments of rock (schist, quartzite, etc.; between 0.5 and $2 \%$ volume) and muscovite (Iglesias-Campos et al. 2014).

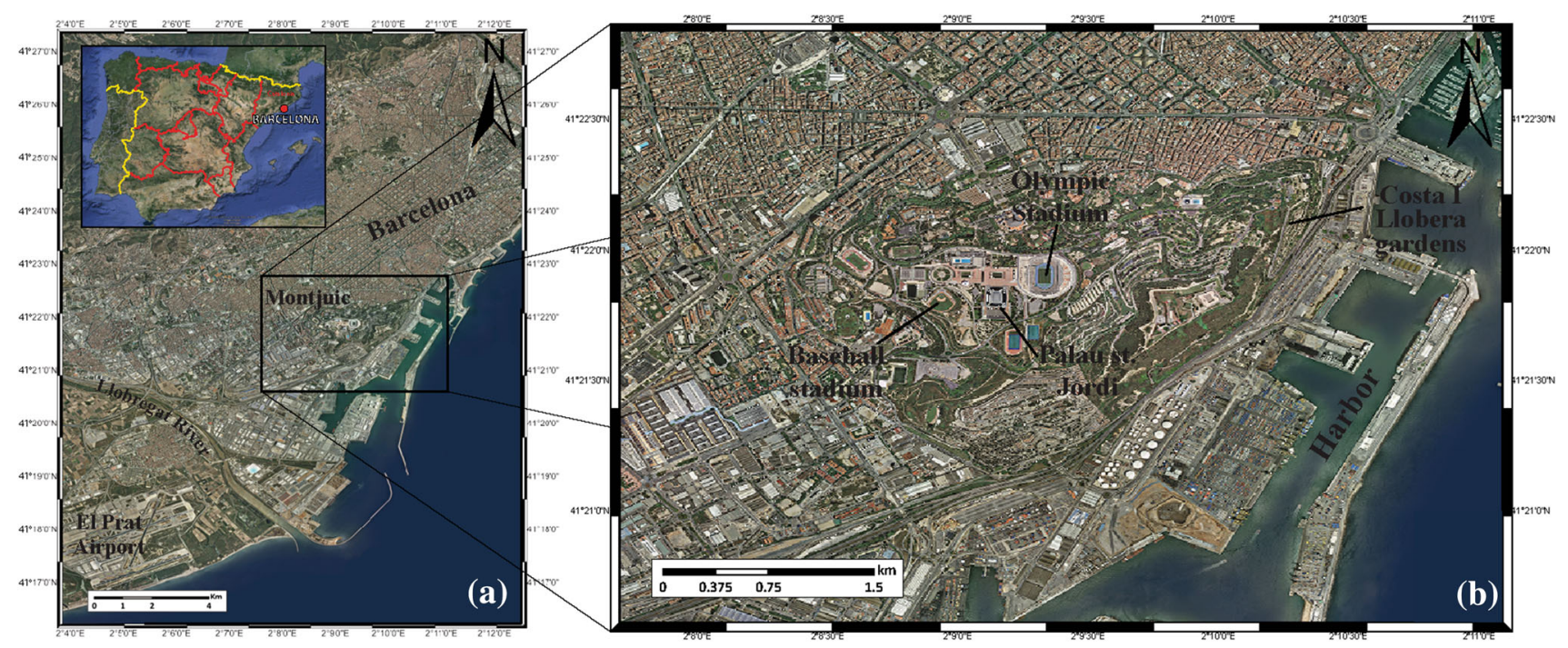

Fig. 1 Geographical position of the hill of Montjuïc. Orthophotos provided by the Catalonia Institute of Cartography and Geology (ICGC) and projected in the coordinate system UTM-WGS84 zone $31 \mathrm{~N}$ 


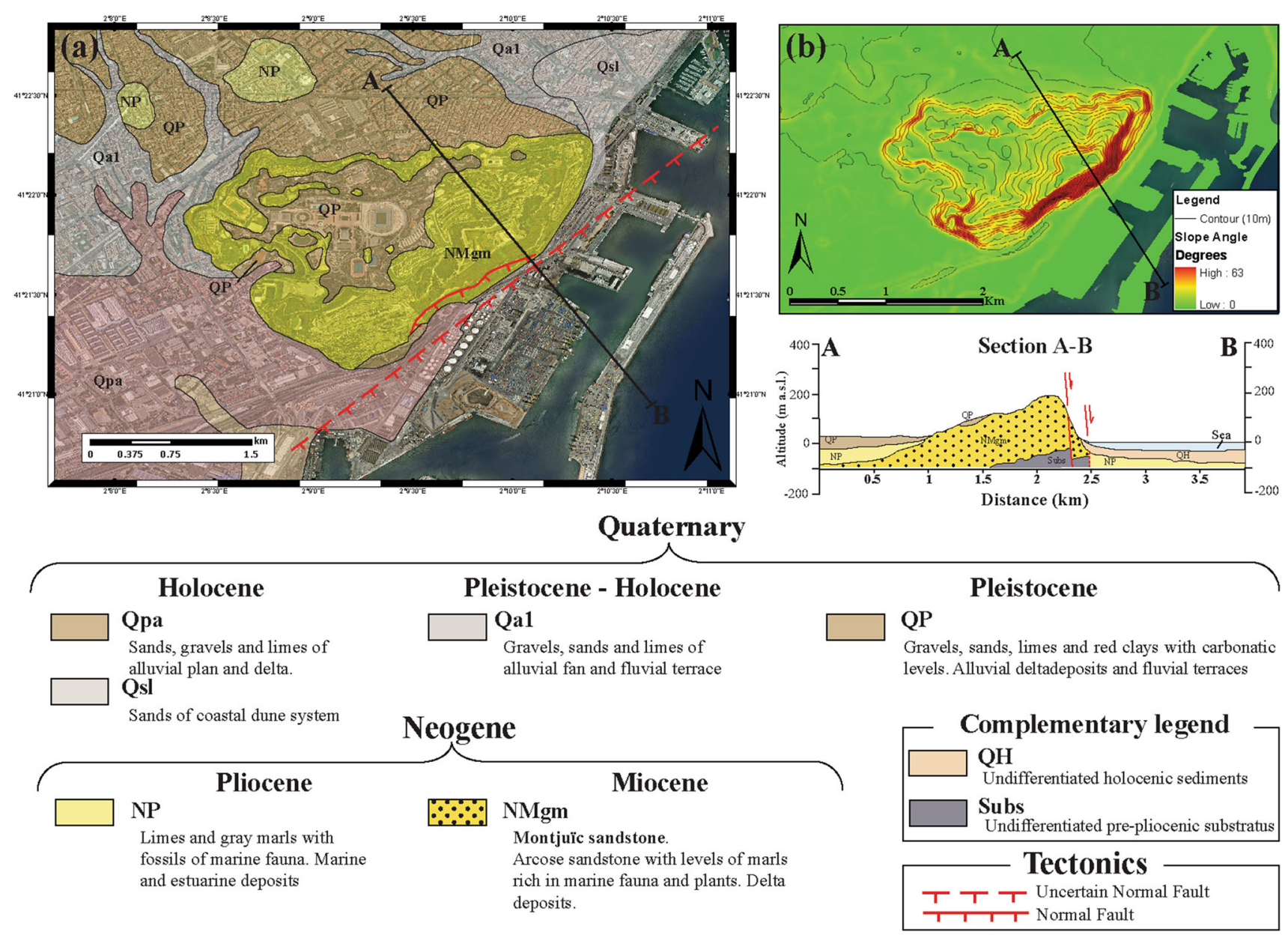

Fig. 2 Extract of the 1:25.000 geological map of the area of Barcelona (a) with geological section $A-B$ of the study area and legend of lithological units (IGC 2010, modified). Top right box (b) shows the slope angle map of the area with contour (equidistance $10 \mathrm{~m}$ )

Due to its lithological composition, an intense mining activity was carried out on the hill, with the development of many sandstone quarries that were, for a long time, the main source of building material for the city. However, these quarries deeply changed the morphology of the hill until they were closed in the early seventies of the twentieth century.

The hill is considered a very important site in Barcelona because it currently hosts several monuments and tourist attractions such as the botanical garden Costa i Llobera, or sport venues built for the 1992 Olympic Games, such as the Palau St. Jordi sporting arena, the Pèrez de Rozas baseball stadium, and the Olympic Stadium.

\section{Materials and methods}

In this study, 28 SAR scenes acquired in StripMap mode and ascending orbit by the $\mathrm{X}$-band $(3.1 \mathrm{~cm}$ wavelength) sensor mounted on the TerraSAR-X satellite were exploited (Table 1). The pixel footprint of these images is approximately $2.5 \mathrm{~m}$ in range (the direction perpendicular to the orbit) and $3.3 \mathrm{~m}$ along-track.

The scene covered by the processed images is approximately 35 by $30 \mathrm{~km}$. The PSIG chain (Crosetto et al. 2011; Devanthéry et al. 2014) was used to generate a set of 56 full resolution (multilook $1 \times 1$ ), multiple-master interferograms spanning the period between 30/12/2007 and $22 / 11 / 2009$, and to perform the PSIG processing over the full scene (Fig. 3a). The selection of the interferograms was based on minimizing the correlation between the perpendicular and temporal baselines in order to increase the sensitivity to topographic height, minimize the amount of decorrelation due to phase gradients, and maximize the effectiveness of the phase unwrapping. A perpendicular baseline threshold of $500 \mathrm{~m}$ was set for this analysis. A precision of 0.07 pixels in azimuth and range was achieved in the co-registration of the images used to generate the interferograms. A spatial low pass filter was used to estimate the atmospheric phase screening (APS), which was 
Table 1 Characteristics of the TerraSAR-X images used in this work: orbit name, acquisition date, time separation with the first image (Btemp) and perpendicular baseline (Bperp)

\begin{tabular}{|c|c|c|c|}
\hline Orbit_Name & $\begin{array}{l}\text { Start_Date } \\
\text { (yyyymmdd) }\end{array}$ & $\begin{array}{l}\text { Btemp } \\
\text { (days) }\end{array}$ & $\begin{array}{l}\text { Bperp } \\
(\mathrm{m})\end{array}$ \\
\hline 3016 & 20071230 & - & - \\
\hline 3183 & 20080110 & 11 & 506,35 \\
\hline 3350 & 20080121 & 22 & 356,85 \\
\hline 3684 & 20080212 & 44 & 297,07 \\
\hline 3851 & 20080223 & 55 & 255,31 \\
\hline 4018 & 20080305 & 66 & 357,69 \\
\hline 4185 & 20080316 & 77 & 252,33 \\
\hline 5187 & 20080521 & 143 & 230,55 \\
\hline 5521 & 20080612 & 165 & 354,08 \\
\hline 5688 & 20080623 & 176 & 334,73 \\
\hline 5855 & 20080704 & 187 & 363,14 \\
\hline 6022 & 20080715 & 198 & 296,16 \\
\hline 6523 & 20080817 & 231 & 251,17 \\
\hline 6857 & 20080908 & 253 & 173,22 \\
\hline 7692 & 20081102 & 308 & 300,79 \\
\hline 8360 & 20081216 & 352 & 343,14 \\
\hline 8861 & 20090118 & 385 & 284,88 \\
\hline 9028 & 20090129 & 396 & 326,35 \\
\hline 9362 & 20090220 & 418 & 239,75 \\
\hline 9696 & 20090314 & 440 & 204,20 \\
\hline 10197 & 20090416 & 473 & 321,13 \\
\hline 10865 & 20090530 & 517 & 326,86 \\
\hline 11533 & 20090713 & 561 & 275,68 \\
\hline 12034 & 20090815 & 594 & 255,19 \\
\hline 12535 & 20090917 & 627 & 419,71 \\
\hline 13036 & 20091020 & 660 & 319,38 \\
\hline 13537 & 20091122 & 693 & 261,72 \\
\hline
\end{tabular}

subsequently removed from the interferograms. The PSIG analysis was performed at full resolution and, at such, a dispersion of amplitude (DA) threshold of 0.3 was used to select the potential Persistent Scatterers (PSs).

The PSIG analysis generated more than 5.4 million PSs. For each PS the main estimated parameters include the average displacement rate or deformation velocity, the deformation time series, and the so-called residual topographic error. This latter parameter plays an important role in the accurate modelling of the PSI observations (i.e., the PSI phases) and for geocoding purposes. The magnitude of the topographic phase component in the PSI phase is reduced by simulating a synthetic topographic phase using a Digital Terrain Model (DTM) of the observed scene, in this study the 30-m DTM generated at the Cartographic Institute of Catalonia. However, any difference between the true height of a PS and the DTM height generates the Residual Topographic Error (RTE) component, which has to be properly modelled, estimated, and separated from the deformation phase component. The estimated RTE is used to obtain an improved geocoding of the PSI products. In fact, the standard PSI geocoding only employs the DTM to geocode its products and does not consider the RTE, which results in geocoding location errors. By using the estimated RTE this kind of error can be largely reduced, and a more precise geocoding achieved. The main parameter considered in this work is the deformation velocity.

To better highlight significant superficial displacements, a 7 classes colorbar ranging between -10 and $+3 \mathrm{~mm} /$ year was chosen to display the PS velocities. Furthermore, based on field validation surveys and taking into account the overall distribution of velocity values in the area, values between -1.5 and $+1.5 \mathrm{~mm} /$ year were conventionally associated to negligible or absent surficial movements.

Points with positive velocity values (blue) indicate displacements towards the satellite, measured along the line of sight, while points with negative velocity values (red) indicate displacements moving away from the satellite, measured along the LOS.

\section{Results and discussion}

The PSIG analysis revealed the existence of some areas showing remarkable surface displacements in Montjuïc (Fig. 3), one near the Palau St. Jordi sporting arena and the Pérez de Rozas baseball stadium (Site 1 in Fig. 3), and another in the area of the Costa i Llobera Gardens (Site 2 in Fig. 3).

In such areas, displacements with velocity values of up to several millimetres per year were measured along the Line-Of-Sight (LOS) of the satellite, and moving away from the satellite (orange and reddish points). These results are discussed in the following paragraphs. Figure 4 shows the RTE map for the Site 1 . The precision of the RTE estimates is of the order of $2 \mathrm{~m}(1 \sigma)$. Considering the acquisition geometry, this value results in a precision of the geocoding (affecting mainly the E-W direction) of $2.65 \mathrm{~m}$ $(1 \sigma)$.

\section{Site 1: Surroundings of the baseball stadium}

Displacement values of up to $12 \mathrm{~mm} /$ year were measured along the satellite LOS in the surroundings of the Palau St. Jordi sporting arena, highlighting diffuse ground deformations that affect all the area surrounding the Pérez de Ròzas baseball stadium (Site 1 in Fig. $3 b$ ). The area appears to be affected by displacements in two separate portions located at the east and west of the baseball stadium, respectively Site 1a and Site 1b in Fig. 5. 

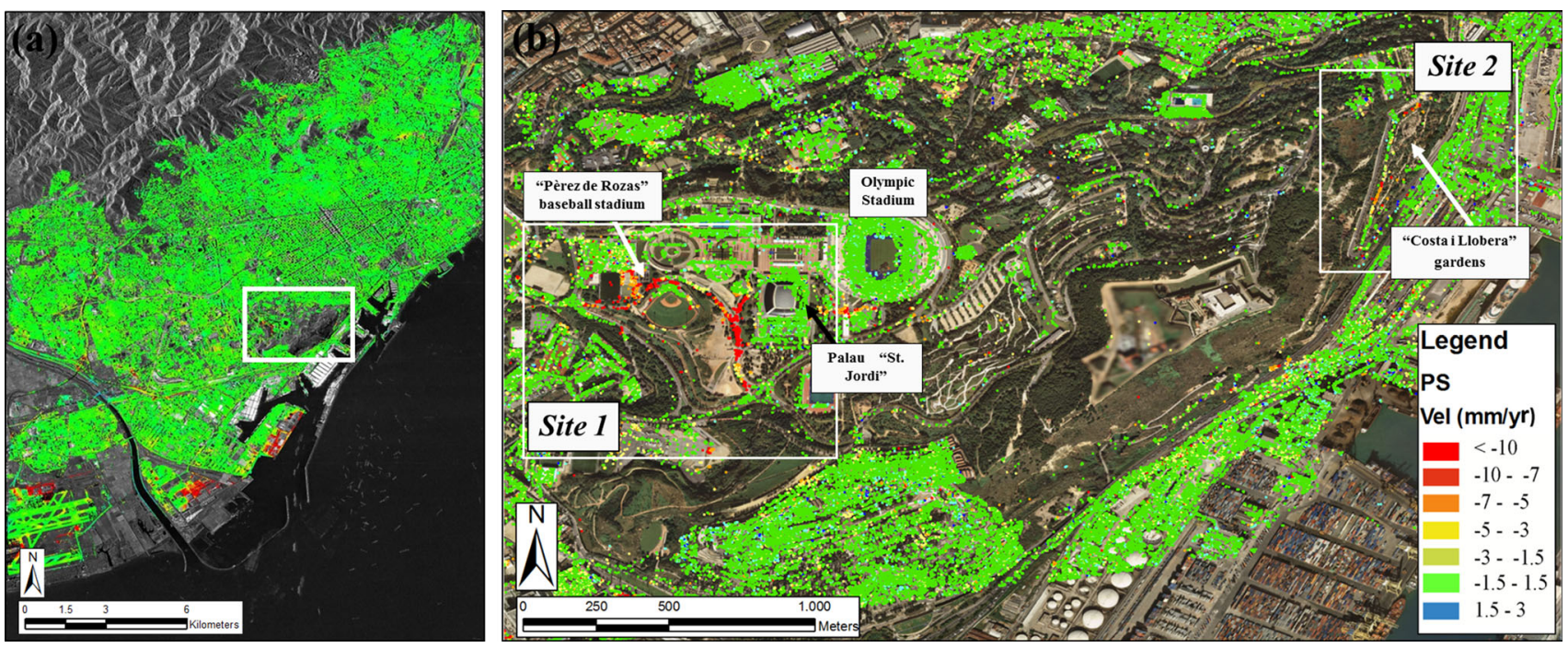

Fig. 3 Geocoded velocity map of the full scene (a) with focus on Montjuïc (b), showing two areas affected by superficial displacements, namely Site 1 and Site 2

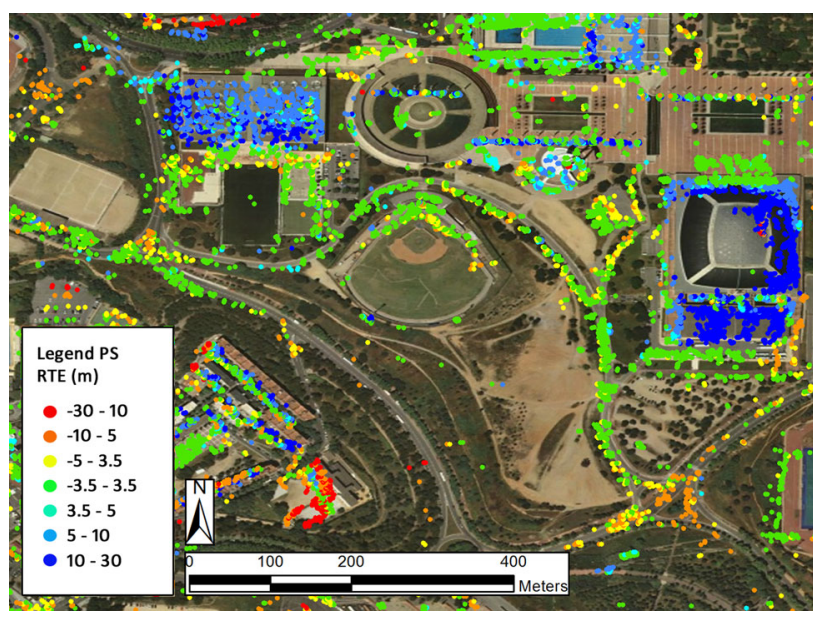

Fig. 4 Geocoded RTE map of the Site 1 shown in Fig. 3

The average linear velocity values measured over the 2-year period range between 4 and $5 \mathrm{~mm} /$ year up to $12 \mathrm{~mm} /$ year in Site 1a (Fig. 5b, c) and up to $11 \mathrm{~mm} /$ year in Site $1 \mathrm{~b}$ (Fig. 5d, e).

A field survey was performed to detect superficial evidence of the ongoing deformation and to assess the state of activity and the extent of the deformation. Figure 5 shows zooms of two areas of Site 1, with pictures taken during the field survey highlighting damage to the streetlights and diffuse cracks on the asphalt. The fracture systems on the asphalt detected during the field survey are well defined, and perfectly follow the limit between the moving and the stable areas as shown by the PSI velocity map (Fig. 5). Moreover, as shown in Fig. 5 (Site 1a), the bleachers of the baseball stadium do not seem to be affected by the general movement of the area, leading to the consideration that the whole superficial deformation in Site 1 could be likely caused by a subsidence phenomenon whose spatial extent is strongly controlled by different subsoil lithology and materials.

The analysis of historical documents and imagery led us to find out that the area was occupied by one of the several sandstone quarries located in Montjuiic. The quarry, called "Cantera Mussol", was active until the mid-twentieth century (Fig. 7), then it became a dump, and totally refilled by garbage.

As shown in Fig. 7 the main quarry faces, drawn in blue dashed line using a 1956 orthophoto, perfectly delimit the area characterized by significant displacements detected with the PSI technique. Therefore, the superficial deformation is the result of the garbage and landfill compaction, which originate diffuse ground movements mainly in the vertical direction. The comparison between displacement Time Series (TS) of two PSs selected as representative (see the white arrows in Fig. 5b), respectively in the vicinity $\left(\mathrm{TS}_{1}\right)$ and in correspondence $\left(\mathrm{TS}_{2}\right)$ of the bleachers of the baseball stadium, show different trends (Fig. 6). In particular, no significant displacement are noticeable on the bleachers $\left(\mathrm{TS}_{2}\right)$ while the surrounding areas $\left(\mathrm{TS}_{1}\right)$ is affected by remarkable deformations.

As a whole, displacement time series of the PSs selected in the unstable part of Site $1\left(\mathrm{TS}_{1}\right.$ and $\mathrm{TS}_{3}$ in Figs. 5, 6) show a general decrease in deformation rate, during the 2 years of acquisition. In fact, from January 2008 to September 2008, the mean settlement velocity in the LOS direction was around $12 \mathrm{~mm} / \mathrm{year}\left(\mathrm{TS}_{3}\right)$ while, from October 2009 until 22 November 2009, the displacement gradually decreased with average values of around $2 \mathrm{~mm} /$ year. This is due to different phases of the garbage landfill 
Fig. 5 Velocity values estimated with the PSIG technique in the surroundings of the Pérez de Ròzas baseball stadium (Site 1). Zooms on the velocity map and photos taken during the field survey are displayed for Site 1a in boxes (b) and (c) and for Site 1b in boxes (d) and (e). The white arrows indicate the location of the PSs whose time series $\left(\mathrm{TS}_{1-2-3}\right)$ are shown in Fig. 6
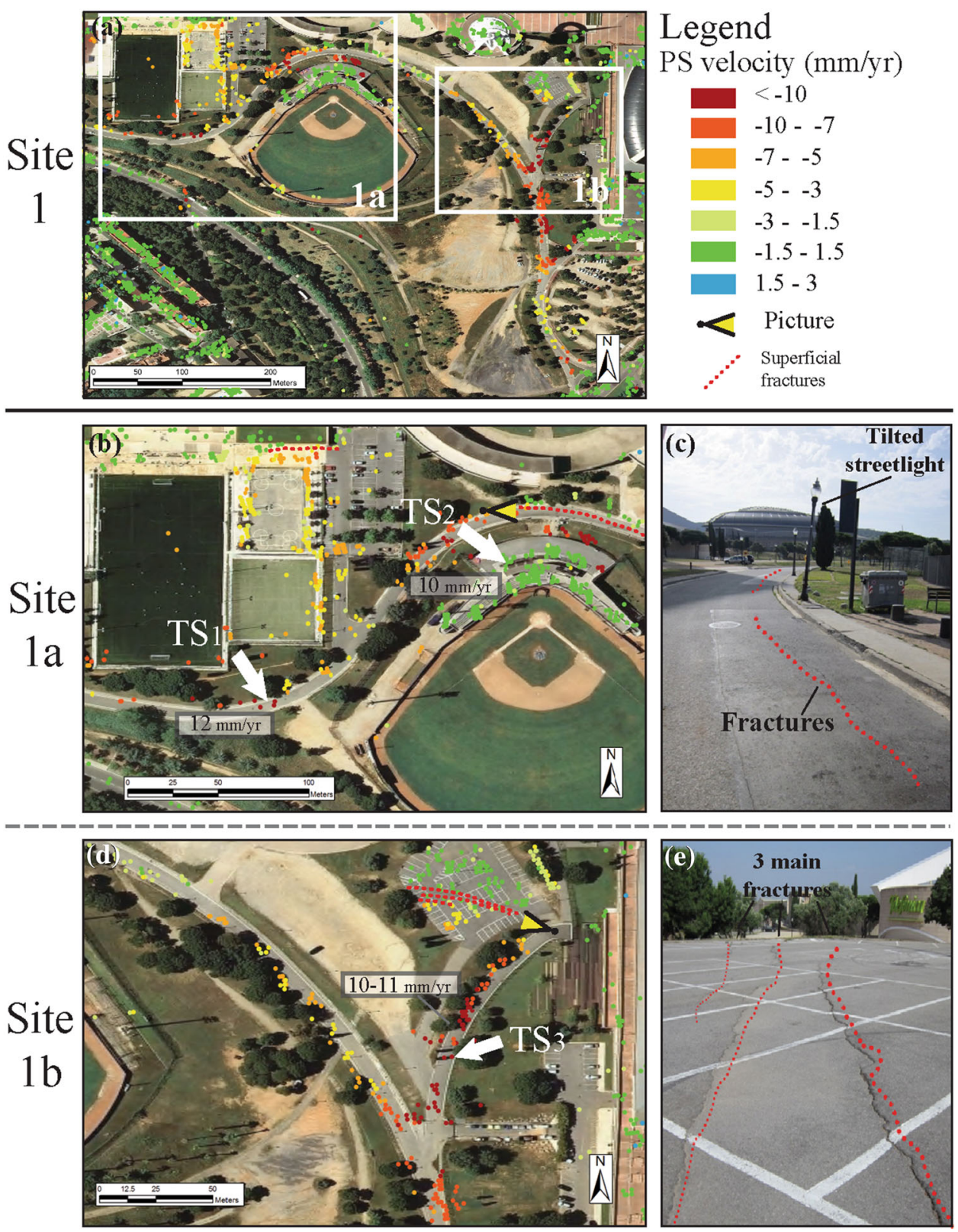

compaction, in response to variations in water content and degradation process of the materials. The surrounding areas, not included in the ancient quarry perimeter are almost completely stable. The bleachers of the baseball stadium do not show significant displacements because their foundation likely lie directly on the undisturbed rock (see Fig. 7).

\section{Site 2: Costa i Llobera gardens}

Evidence of superficial displacements have been detected also near the Costa i Llobera Gardens (see Site 2 in
Figs. 3, 8a). Interferometric data allowed to highlight movement in two portions of this area, the first one (Site $2 \mathrm{a}$ in Fig. 8) affects the Miramar Road and a portion of the underlying gardens, while the second one (Site $2 b$ in Fig. 8) is located next to the entrance of the tunnel on Miramar Road. In this case, the area is situated on a steep slope and, for this reason, the movement can be assumed to be along the main slope direction. The average velocity values in Site $2 \mathrm{a}$, measured along the satellite LOS, range between 4 and $5 \mathrm{~mm} /$ year on the road floor and in the underlying gardens. The interferometric analysis allowed processing a significant number of points on the road but, unfortunately, it was impossible to obtain a sufficient PS 
Fig. 6 Deformation time series (TS) of three PSs selected in Site 1 . Their location is indicated by the white arrows shown in boxes (b) and (d) of Fig. 5

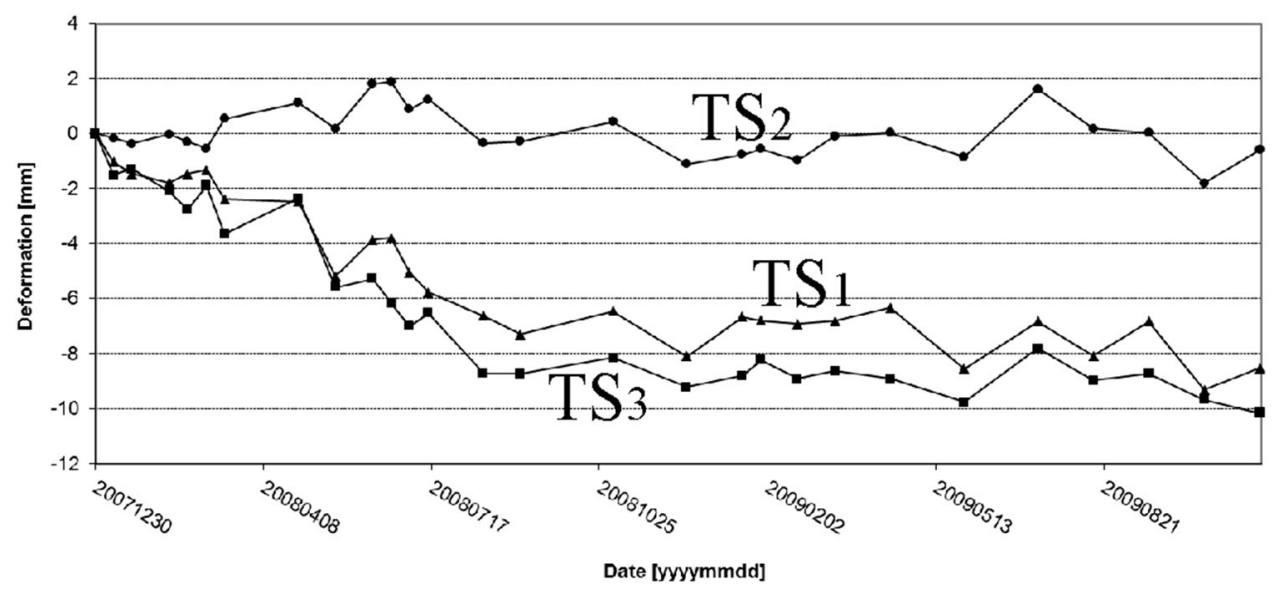

Fig. 7 Historical orthophoto (1956) showing the area affected by superficial deformation in the hill of Montjuïc. In the picture, the main quarry faces are drawn in blue dashed line, to highlight the perfect spatial matching between the moving area detected by the PSI technique and the location of the old quarry. The position of Site 1a and Site $1 \mathrm{~b}$ is indicated to facilitate the interpretation (Source Diputaciò de Barcelona, WMS service)

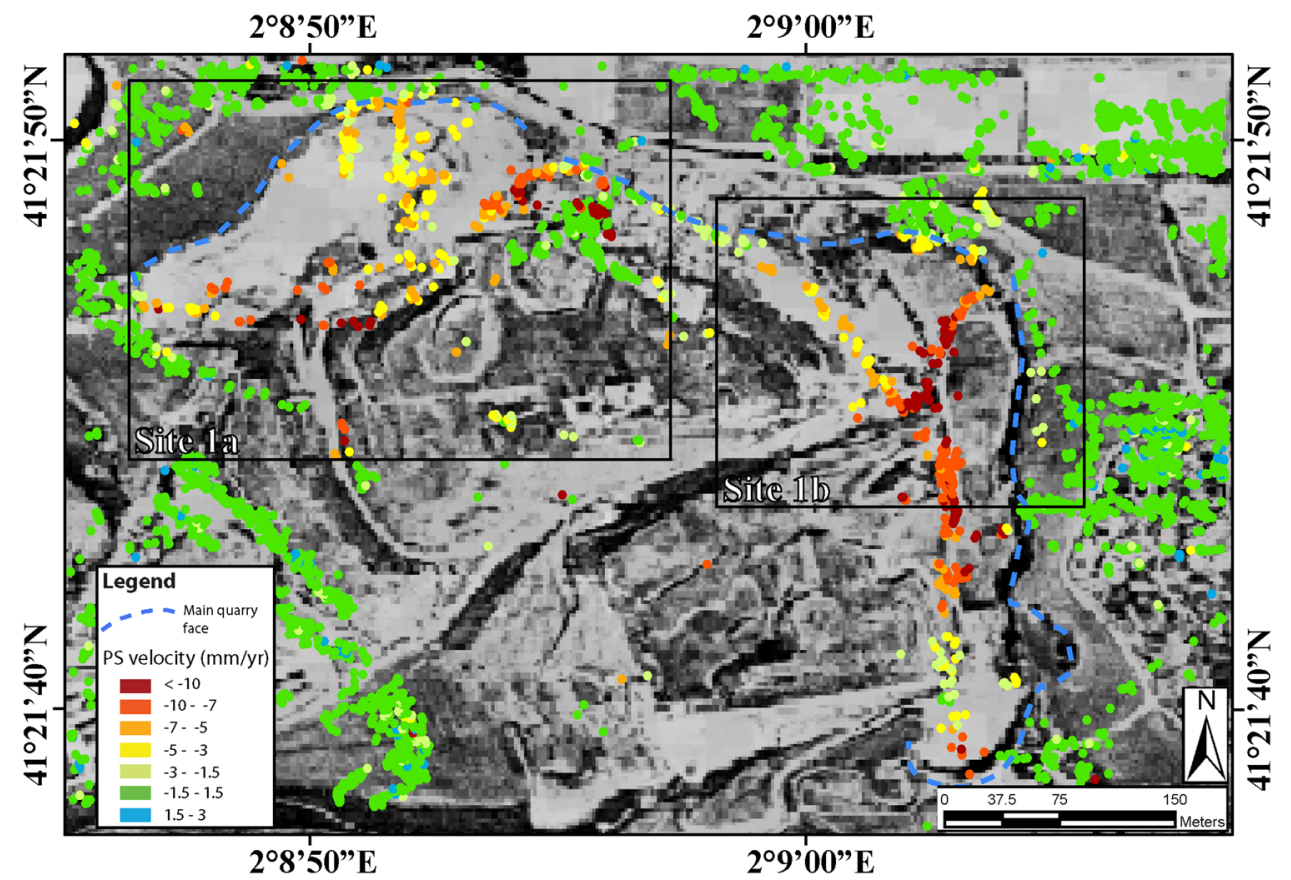

density in the area of the gardens due to the presence of dense vegetation. This fact prevents an accurate delimitation of the moving area in Site 2a.

Site $2 \mathrm{a}$ is characterized by a rocky cliff and an underlying steep slope where the gardens are located. As observed during a field survey performed in June 2013, the cliff consists in a wide outcrop of "Montjuïc Sandstone" with levels of marls (Fig. 8, box c), whose rockfall sediment originated a large deposit at the foot. Furthermore, the area was occupied in the past by a sandstone quarry, whose waste materials contributed to increase the thickness of the slope deposits at the base of the cliff.

Taking into account the geological and geomorphological setting of the slope and the information collected during the field survey, the cause of the displacements is attributed to the instability of these deposits, that are moving as a landslide with an "extremely low" deformation rate, according to Cruden and Varnes (1996).

The deformation rate is highlighted by the comparison between the time series (TS) of two selected PSs, one stable and the other affected by deformation, as shown in Fig. 9. The comparison between the two graphs confirms the entity of the movement in Site 2a, which has an intensity characterized by a general decrease. This decrease could be mainly due to two causes: (1) simple decrease of landslide velocity; (2) a small variation in landslide movement direction, causing a reduction of the displacement component measured along the satellite LOS.

A second moving portion of the gardens named Site $2 b$ (boxes $d$ and e of Fig. 8) is located near a small car park situated next to the entrance of the tunnel on Miramar Road and is characterized by velocity values from 4.5 up to 
Fig. 8 Velocity values estimated with the PSIG technique in the surroundings of the Costa i Llobera gardens (Site 2). Zooms on the velocity map and photos taken during the field survey are displayed for Site $2 \mathrm{a}$ in boxes (b) and (c) and for Site $2 \mathrm{~b}$ in boxes (d) and (e). The white arrows indicate the location of the PSs whose time series $\left(\mathrm{TS}_{1-2}\right)$ are shown in Fig. 9
Fig. 9 Deformation time series of two PSs from the Site 2. Their location is indicated by the white arrows shown in Fig. 8

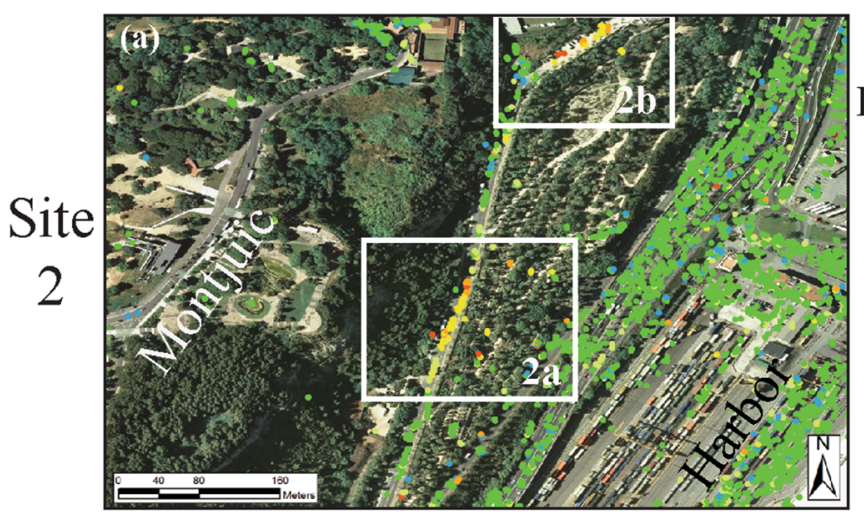

Legend

PS velocity $(\mathrm{mm} / \mathrm{yr})$
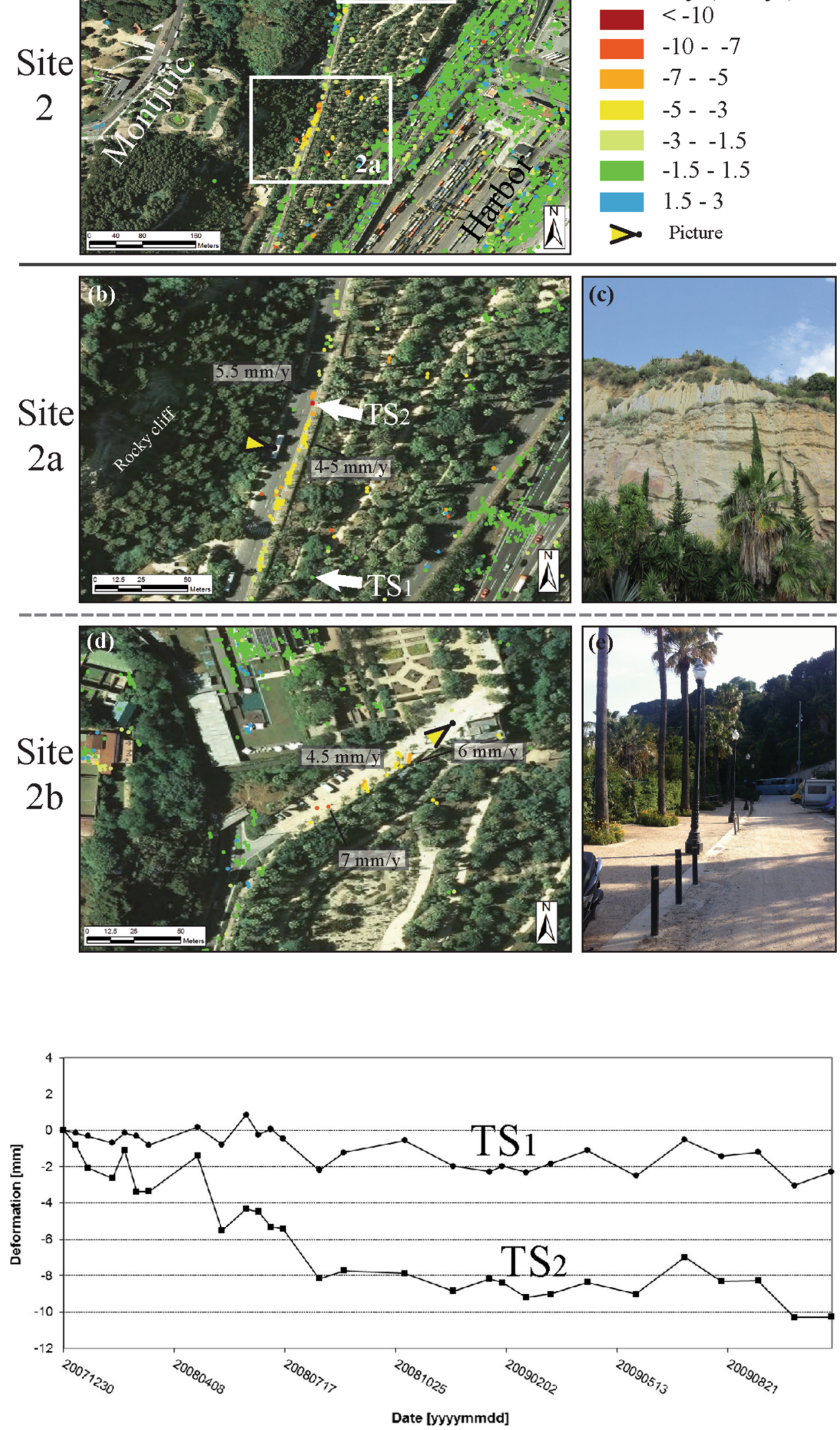
$7 \mathrm{~mm} /$ year (in LOS direction). As mentioned for Site 2a, the low PS density obtained in the slope did not allow the identification of the exact perimeter of the moving area. Nevertheless, based on the general distribution of the velocity values, the displacement appears to be limited to the edge of the car park area and a narrow zone downslope. A field survey was carried out in the underlying portion of the Costa i Llobera garden, but no evident signs of superficial deformation were detected, probably due to the continuous maintenance activity in the gardens. We found out that this part of the slope is made by an artificial landfill, composed of sandstone boulders, among a matrix of finer and poorly consolidated material. Thus, although an accurate delimitation of the phenomenon based on the radar data and the field survey results are impossible, the ongoing deformation can be assumed to have a small extent affecting part of the artificial slope on which the car park is placed.

\section{Conclusions}

This study has been focused on the analysis of PSI results obtained for the hill of Montjuïc (Barcelona, Spain). In particular, the results were generated from 28 Stripmap TerraSAR-X images, covering the period from December 2007 to November 2009, processed with the PSIG chain.

The PSI velocity map has proven to be very effective in order to detect superficial deformation processes, allowing the detection of deformation processes on the top and the eastern flank of the hill of Montjuï. Such deformation processes, ongoing during the period of acquisition of the satellite images, were subsequently characterized and interpreted by analysing the measured velocity values and performing field surveys. In the area surrounding the Palau St. Jordi sporting arena and the baseball stadium, named Site 1 , the analysis of historical images has been crucial to understand the causes of the deformation, related to the compaction of the garbage landfill in an ancient sandstone quarry. Unfortunately, further information about the exact thickness of the landfill and the depth of the underlying bedrock were not available since they can be obtained only using geophysical methods, but they were not considered for this project.

The deformation process ongoing in Site 1 shows displacement, highlighted by cracks on the surface and damaged streetlights and road floors, with velocities of up to $12 \mathrm{~mm} /$ year (in the LOS direction).

In the second site (Site 2), near the gardens of Costa $i$ Llobera, lower displacement rates $(5-7 \mathrm{~mm} /$ year) were detected in two distinct areas related to different causes. Unfortunately, the presence of dense vegetation did not allow obtaining a uniform distribution of PSs on the entire areas of interest. Nevertheless, taking into account the information provided by the velocity map and performing a focused field survey, the two moving areas in Site 2 are interpreted as slope processes. The first one (Site 2a) is larger and mainly caused by instability of the slope deposits at the foot of a rock cliff, and the second one (Site 2b), smaller in size, is due to the instability of a landfill with a small car park on top.

On the whole, this work contributes to providing a further example of the effectiveness of the integration between high-resolution PSI and historical data and maps, to detect, measure, and interpret different types of ground deformation phenomena.

Acknowledgments This work is the result of a cooperation between the Department of Earth Sciences of the University of Florence and the Geomatics Division of CTTC (Centre Tecnològic de Telecomunicacions de Catalunya). Twenty of the 28 TerraSAR-X SAR images used in the Barcelona case study were acquired within the Project "Evaluation of DEM derived from TerraSAR-X data, LAN0634", of the TerraSAR-X Science Service Program.

Open Access This article is distributed under the terms of the Creative Commons Attribution 4.0 International License (http://crea tivecommons.org/licenses/by/4.0/), which permits unrestricted use, distribution, and reproduction in any medium, provided you give appropriate credit to the original author(s) and the source, provide a link to the Creative Commons license, and indicate if changes were made.

\section{References}

Alfaro A, Pujades LG, Goula X, Susagna T, Navarro M, Sànchez J, Canas JA (2001) Preliminary map of soil's predominant periods in Barcelona using microtremors. Pure Appl Geophys 158:2499-2511

Berardino P, Fornaro G, Lanari R, Sansosti E (2002) A new algorithm for surface deformation monitoring based on small baseline differential SAR interferograms. IEEE TGARS 40(11):2375-2383

Colesanti C, Wasowski J (2006) Investigating landslides with spaceborne Synthetic Aperture Radar (SAR) interferometry. Eng Geol 88:173-199

Crosetto M, Monserrat O, Iglesias R, Crippa B (2010) Persistent Scatterer Interferometry: potential, limits and initial C- and X-band comparison. Photogramm Eng Remote Sens 76(9):1061-1069

Crosetto M, Monserrat O, Cuevas M, Crippa B (2011) Spaceborne differential SAR interferometry: data analysis tools for deformation measurement. Remote Sens 3:305-318

Cruden DM, Varnes DJ (1996) Landslide types and processes. In: Turner AK, Schuster RL (eds) Landslides: investigation and Mitigation, Sp. Rep. 247, Transportation Research Board, National research Council. National Academy Press, Washington DC, pp 36-75

Devanthéry N, Crosetto M, Monserrat O, Cuevas-González M, Crippa B (2014) An approach to Persistent Scatterer Interferometry: the PSIG chain. Remote Sens 6:6662-6679. doi:10.3390/rs6076662

Diputaciò de Barcelona, WMS services. http://www.diba.cat/web/ idebarcelona/serveis-de-mapes-wms

Dixon TH, Amelung F, Ferretti A, Novali F, Rocca F, Dokkas R, Sella G, Kim SW, Wdowinski S, Whitman D (2006) Subsidence and flooding in New Orleans. Nature 441:587-588 
Farina P, Colombo D, Fumagalli A, Marks F, Moretti S (2006) Permanent Scatterers for landslide investigations: outcomes from the ESA-SLAM project. Eng Geol 88:200-217

Ferretti A, Prati C, Rocca F (2000) Nonlinear subsidence rate estimation using permanent scatterers in differential SAR interferometry. IEEE Trans Geosci Remote Sens 38(5):2202-2212

Ferretti A, Novali F, Bürgmann R, Hilley G, Prati C (2004) InSAR permanent scatterer analysis reveals ups and downs in San Francisco Bay area. Eos Trans Am Geophys Union 85(34):317-324

Galloway DL, Burbey TJ (2011) Review: regional land subsidence accompanying groundwater extraction. Hydrogeol $\mathrm{J}$ 19:1459-1486

Hanssen R (2001) Radar interferometry. Kluwer Academic Publishers, Dordrecht

Iglesias-Campos MA, Garcìa-Fortes S, Prada-Perez JL (2014) Influence of projection angle in sandblasting cleaning on detrictic stone materials in Architectural Heritage. Materiales de Construcción 64(314):e021 April-June 2014, ISSN-L: 0465-2746

Institut Cartogràfic I Geològic de Catalunya, web page and WMS services. http://www.icc.cat/cat/Home-ICC/Geoinformacio-digi tal/Serveis-en-linia-Geoserveis/WMS-de-cartografia-raster

Institut Geològic de Catalunya (2010) Geologia del Pla de Barcelona des de l'Observatori Fabra. http://www.igc.cat/web/files/ 201010_igc_racab_plafo_fabra.pdf
Lourenço PB, Ramos LF, Vasconcelos G (2004) On the cyclic behaviour of stone dry masonry joints. In: 13th international brick and block masonry conference, Amsterdam, July 4-7, 2004

Lu P, Casagli N, Catani F, Tofani V (2012) Persistent Scatterers Interferometry Hotspot and Cluster Analysis (PSI-HCA) for detection of extremely slow-moving landslides. Int J Remote Sens 33(2):466-489

Lubitz C, Motagh M, Wetzel HU, Kaufmann H (2013) Remarkable urban uplift in staufen im Breisgau, Germany: observations from TerraSAR-X InSAR and leveling from 2008 to 2011. Remote Sens 5(6):3082-3100. doi:10.3390/rs5063082

Massonnet D, Feigl KL (1998) Radar interferometry and its application to changes in the earth's surface. Rev Geophys 36:441-500

Ng HM, Ge L, Li X, Zhang K (2012) Monitoring ground deformation in Beijing, China with persistent scatterer SAR interferometry. J Geod 86(6):375-392

Parcerisa Duocastella D, Thiry M, Gòmez-Gras DM, Calvet F (2001) Proposition d'un modele de silicification superficielle des gres neogenes de Montjuic, Barcelone (Espagne): parageneses minerales, environments geochimiques et circulation des fluids. Bulletin de la Société Géologique de France 172(6):751-764, ISSN 0037-9409 